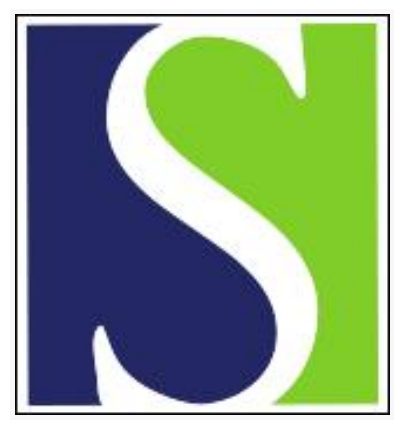

Scand J Work Environ Health 2012;38(2):89-91

https://doi.org/10.5271/sjweh.3277

Published online: 30 Jan 2012, Issue date: Mar 2012

\title{
How should methods for return to work be evaluated?
}

by Järvholm B

Affiliation: Department of Public Health and Clinical Medicine, Umeå University, SE-901 85 Umeå, Sweden. bengt.jarvholm@envmed.umu.se

Refers to the following texts of the Journal: 2012;38(2):93-104 2012;38(2):134-143 2012;38(2):120-133 2005;31(5):367-374 2010;36(6):473-483 2010;36(6):488-498 2011;37(3):186-195 2011;37(6):481-493

The following article refers to this text: 2013;39(1):37-45

Key terms: editorial; effect evaluation; evaluation; process evaluation; return to work; return-to-work; RTW; sick leave; sickness absence; work ability

This article in PubMed: www.ncbi.nlm.nih.gov/pubmed/22290029

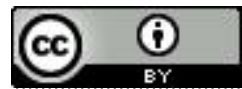




\section{How should methods for return to work be evaluated?}

Measures to decrease early retirement are underway in many countries to increase the working population and lower costs. Sick leave is the normal pathway to early retirement and methods to enable persons on sick leave to return to work (RTW) earlier and at a higher rate are in focus. Using the term "RTW", a search in PubMed resulted in about 300 papers, of which more than half have been published after 2008 and $20 \%$ during the last year alone.

RTW has been the focus of many papers recently submitted to and published in the Scandinavian Journal of Work, Environment and Health (eg, 1, 2, 3). In this issue, Aust and coworkers (4) describe a large randomized Danish study to investigate if support by a trained staff will increase RTW. It is probably the largest ongoing RTW evaluation at the moment. The design is similar to studies of pharmaceutical drugs in phase III, involving a multicenter approach, evaluation committee, cost-benefit analyses, trial registration, and a huge budget. In contrast to most previous studies, it does not focus on a single diagnosis but on estimated prognosis. Established after a literature review, the intervention method is described as "biopsychosocial" (5). Compared to most other studies in this area, the Aust et al study (4) has a high power. A recent systematic review of community and work-based measures to reduce sick leave among persons with musculoskeletal disorders found that the published literature consisted of rather small studies of limited quality. Furthermore, the effect was overestimated through biased publishing of positive studies (6).

Modifications to work and contacts with the employer are often emphasized as important for RTW. Decreasing working time and changing work tasks increased RTW in a Finnish controlled study of persons with musculoskeletal disorders (7), and stress management at work decreased absenteeism in a Danish study (8). Furthermore, a randomized study of persons with severe psychiatric illness involving six countries found that individual support involving contact with the employer increased the chance for RTW (9). In contrast, contact with healthcare doctors seem to be of limited importance for RTW (10). In fact, a small controlled trial where less experienced doctors were trained by more senior colleagues actually increased the sick leave (11).

It would be of great interest to understand better the mechanistic aspects of contacts with employers for RTW. One cause may be modification of the workplace or tasks, but it can also be that the employer is persuaded to accept a lower productivity. It is probable that people on sick leave have lower productivity and the decrease may persist also when returning to work. Persons who returned to work from sick leave for low-back pain were found to have a lower productivity still 12 months after the sick leave ended (12).

While there is a high interest to increase RTW, there are few studies of the adverse effects of too early RTW. In 1955, when sick leave was granted to the entire population in Sweden through a governmentfinanced system, a major argument was to protect the sick worker from further impairment due to harmful factors at work and enable a more rapid recovery (13). In a recent report, even the OECD acknowledged the need for people to be on sick leave and argued "cutting benefit entitlements for people who are already suffering from ill-health and forcing them to undergo training or even seek work is both highly unpopular and not fair for some groups" (14). However, they did not define the "groups" that should be on sick leave. Adverse effects may be through presenteeism (ie, coming to work when sick) or unemployment.

Presenteeism is a predictor of impaired health at least in some circumstances (15). A sick person may 
be susceptible to harm from occupational factors that normally do not harm healthy persons. A study by Kivimäki et al (16) found that severe coronary events were more common among unhealthy persons without sickness absence compared to unhealthy persons with sickness absence. The Viikari-Juntura et al study (7) indicated no adverse effects of early RTW as interruption of part-time sick leave due to exacerbation of symptoms or in symptom severity. It is argued that work is good for mental health (14), while a study found that disability pension seemed to improve mental symptoms especially among those with chronic diseases (17). There are probably people on sick leave whose health is improved by being on sick leave, individuals whose health is impaired by being on sick leave, and individuals whose health neither improves nor declines. An ideal method for the evaluation of RTW should be able to identify those whose health is impaired by too early RTW.

Unemployment may be an adverse effect of RTW as there are indications that unemployment per se impairs health (18). It is uncertain if RTW is a benefit to everyone who moves from being patients on sick leave to clients in job centers. From a work labor perspective, it is often argued that unemployment is better than sick leave as the latter may lead to permanent withdrawal from the work force due to disability pension (14). Adverse effects occurring after several years are especially difficult to study, but the Nordic countries have probably better chances to conduct such studies due to their good data registers.

RTW programs may strongly depend on context. Programs that work in countries and time periods in which there is a shortage of manpower may work differently under other circumstances. While good pharmaceutical studies usually are considered to have a strong external validity, RTW studies with a good external validity have to focus on a variable context.

There is a need to develop effective methodologies for evaluation of RTW. Just copying the corresponding methodologies for pharmaceutical drugs is not enough. Studying adverse effects and contextual factors and understanding mechanisms are often a greater challenge in RTW studies over and above difficulties relating to blinding and randomization. The Danish study is a step forward and will probably set a new standard, but there is always room for progress.

\section{References}

1. Dekkers-Sánchez PM, Wind H, Sluiter JK, Frings-Dresen MHW. What promotes sustained return to work of employees on long-term sick leave? Perspectives of vocational rehabilitation professionals. Scand J Work Environ Health. 2011;37(6):481-493. http://dx.doi.org/10.5271/sjweh.3173.

2. Young AE. Return to work following disabling occupational injury - facilitators of employment continuation. Scand $\mathbf{J}$ Work Environ Health. 2010;36(6):473-483. http://dx.doi.org/10.5271/sjweh.2986.

3 Rebergen DS, Bruinvels DJ, Bos CM, van der Beek AJ, van Mechelen W. Return to work and occupational physicians' management of common mental health problems - process evaluation of a randomized controlled trial. Scand J Work Environ Health. 2010;36(6):488-498. http://dx.doi.org/10.5271/sjweh.3084.

4. Aust B, Helverskov T, Nielsen MB, Bjorner JB, Rugulies R, Nielsen K, et al. The Danish national return-to-work program - aims, content, and design of the process and effect evaluation. Scand J Work Environ Health. 2012;38(2):120-133. http:// dx.doi.org/10.5271/sjweh.3272.

5. Andersen MF, Nielsen KM, Brinkmann S. Meta-synthesis of qualitative research on return to work among employees with common mental disorders. Scand J Work Environ Health. 2012;38(2):93-104. http://dx.doi.org/10.5271/sjweh.3257.

6. Palmer KT, Harris EC, Linaker C, Barker M, Lawrence W, Cooper C, et al. Effectiveness of community- and workplace-based interventions to manage musculoskeletal-related sickness absence and job loss--a systematic review. Rheumatology (Oxford). 2012 Feb;51(2):230-42. Epub 2011 Mar 16.

7. Viikari-Juntura E, Kausto J, Shiri R, Kaila-Kangas L, Takala EP, Karppinen J, et al. Return to work after early part-time sick leave due to musculoskeletal disorders: a randomized controlled trial. Scand J Work Environ Health. 2012;38(2):134-143. http://dx.doi.org/10.5271/sjweh.3258.

8. Willert MV, Thulstrup AM, Bonde JP. Effects of a stress management intervention on absenteeism and return to work-results from a randomized wait-list controlled trial. Scand J Work Environ Health. 2011;37(3):186-95. http://dx.doi. org/10.5271/sjweh.3130. 
9. Burns T, Catty J, Becker T, Drake RE, Fioritti A, Knapp M, et al. The effectiveness of supported employment for people with severe mental illness: a randomised controlled trial. Lancet. 2007;370(9593):1146-52. http://dx.doi. org/10.1016/S0140-6736(07)61516-5.

10. Lötters FJ, Foets M, Burdorf A. Work and health, a blind spot in curative healthcare? A pilot study. J Occup Rehabil. 2011;21(3):304-12. http://dx.doi.org/10.1007/s10926-010-9271-3.

11. Faber E, Bierma-Zeinstra SM, Burdorf A, Nauta AP, Hulshof CT, Overzier PM, et al. In a controlled trial training general practitioners and occupational physicians to collaborate did not influence sickleave of patients with low back pain. J Clin Epidemiol. 2005;58(1):75-82. http://dx.doi.org/10.1016/j.jclinepi.2004.04.015.

12. Lötters F, Meerding WJ, Burdorf A. Reduced productivity after sickness absence due to musculoskeletal disorders and its relation to health outcomes. Scand J Work Environ Health. 2005;31(5):367-74. http://dx.doi.org/10.5271/ sjweh.920.

13. Järvholm B, Karlsson B, Mannelqvist R. [Work capacity in the health insurance--how the concept is described in the legislation]. Lakartidningen. 2009;106(17):1178-81.

14. Organisation for Economic Co-operation and Development. Sickness, Disability and Work: Breaking the Barriers A Synthesis of Findings across OECD Countries: OECD Publishing; 2010. 166 s. p.

15. Gustafsson K, Marklund S. Consequences of sickness presence and sickness absence on health and work ability: a Swedish prospective cohort study. Int J Occup Med Environ Health. 2011;24(2):153-65. http://dx.doi.org/10.2478/s13382-0110013-3.

16. Kivimäki M, Head J, Ferrie JE, Hemingway H, Shipley MJ, Vahtera J, et al. Working while ill as a risk factor for serious coronary events: the Whitehall II study. Am J Public Health. 2005;95(1):98-102. http://dx.doi.org/10.2105/ AJPH.2003.035873

17. Westerlund H, Vahtera J, Ferrie JE, Singh-Manoux A, Pentti J, Melchior M, et al. Effect of retirement on major chronic conditions and fatigue: French GAZEL occupational cohort study. BMJ. 2010;341:c6149. http://dx.doi.org/10.1136/bmj. c6149

18. Roelfs DJ, Shor E, Davidson KW, Schwartz JE. Losing life and livelihood: a systematic review and metaanalysis of unemployment and all-cause mortality. Soc Sci Med. 2011;72(6):840-54. http://dx.doi.org/10.1016/j. socscimed.2011.01.005

Bengt Järvholm

Department of Public Health and Clinical Medicine

Umeå University

SE-901 85 Umeå

Sweden

[E-mail: bengt.jarvholm@envmed.umu.se] 
